\title{
Influential Factors in Crude Oil Price Forecasting
}

\author{
July 12,2017
}

\begin{abstract}
This paper identifies factors that are influential in forecasting crude oil prices. We consider six categories of factors (supply, demand, financial market, commodities market, speculative, and geopolitical) and test their significance in the context of estimating various forecasting models. We find that the Least Absolute Shrinkage and Selection Operator (LASSO) regression method provides significant improvements in the forecasting accuracy of prices compared to alternative benchmarks. Relative to the no-change and future-based models, LASSO forecasts at the 8-step ahead horizon yield significant reductions in Mean Squared Prediction Error (MSPE), with MSPE ratios of 0.873 and 0.898 , respectively. We also document substantial improvements in forecasting performance of the factor-based model that employs only a subset of variables chosen by LASSO. Finally, the time-varying nature of the relationship between factors and oil prices are used to explain recent movements in crude oil prices.
\end{abstract}

Keywords: Oil Prices; Forecasting; Least Absolute Shrinkage and Selection Operator (LASSO); Mean Squared Prediction Error (MSPE); Success Ratio 


\section{Introduction}

Crude oil is widely considered to be one of the most important commodities affecting global economic growth. Estimates indicate that the oil and gas drilling sector makes up about three percent of global GDP ${ }^{1}$, and imports of petroleum products account for about forty percent of U.S. trade deficits. ${ }^{2}$. Movements in crude prices have been shown to signficantly impact the world economy at various levels, from family budgets to corporate earnings and to the nation's economy (c.f. Eika and Magnussen, 2000; Kilian, 2009). According to IMF, a $10 \%$ increase in oil prices results in a $0.2 \%$ drop in global GDP. Therefore, when oil prices reached a record high of $\$ 145 / \mathrm{bbl}$ in 2008, and then began to drop sharply beginning 2014 and reaching a low of $\$ 29 / \mathrm{bbl}$ in early 2016, this resulted in significant revenue shortfalls and economic stress on many energy exporting nations such as Russia and Saudi Arabia. On the other hand, the availability of cheaper oil has been hailed as a potent economic stimulus to many net oil importer countries such as China and India, while keeping inflation under check.

Given the central role of oil in the economy there is a great deal of attention in the literature in forecasting crude prices. According to a recent Wall Street Journal article, "forecasting is always an inexact art, particularly for oil, a global industry with wildly uneven data...it is a crucial one, underpinning companies' decisions about when to drill and how much to hedge," and importantly, "market watchers get this so wrong."?3

One of the most watched oil price forecast is from the US Energy Information Administration (EIA), which formally constructs monthly and quarterly forecasts of the price of crude oil at horizons up to two years $4^{4}$. Although EIA's short-term forecasts help inform corporate investment and guide resource deployment decisions, their forecasts are often hard to replicate and inaccurate. For instance, EIA reported a price projection of about $\$ 28 / \mathrm{bbl}$

\footnotetext{
${ }^{1}$ http://data.worldbank.org/indicator/NY.GDP.PETR.RT.ZS

${ }^{2}$ https://www.census.gov/foreign-trade/Press-Release/current_press_release/index.html

${ }^{3}$ What Went Wrong in Oil-Price Forecasts? By Nicole Friedman, Dec. 10, 2015, Wall Street Journal. http://www.wsj.com/articles/what-went-wrong-in-oil-price-forecasts-1449794306

${ }^{4} \mathrm{http}: / /$ www.eia.gov/forecasts/steo/
} 
in 2010, yet the actual average price for oil traded on the New York Mercantile Exchange in 2010 was $\$ 79.61 /$ bbl. Ironically, right before the sharp fall of oil prices in mid-2014, EIA raised its 2014 forecast on WTI crude-oil prices to nearly $\$ 96 /$ bbl..$^{5}$ In a letter defending the veracity of EIA reports, Howard Gruenspecht, deputy administrator of the EIA, commented that, "EIA does not characterize any of its long run projection scenarios as a forecast." ${ }^{6}$

Futures-based forecasts provide a market-based expectation of oil prices. Although in principle the futures market should be a good predictor of future spot prices, this is not supported by empirical evidence. Alquist and Kilian (2010) document that oil futures prices tend to be less accurate in the mean-squared prediction error sense than a simple no-change forecast (which posit that oil prices will be the same tomorrow as they are today).

Various econometric approaches have been proposed to forecast oil prices. For example, in an attempt to improve forecasting performancey, Pindyck (1999) adds a mean reversion term to a deterministic linear trend model. Radchenko (2005) applies a shifting trend model with an autoregressive process in error terms instead of the white noise process. Still others apply ARIMA models to forecast the monthly WTI crude oil prices. However, such forecasting methods have not been particularly successful when compared with the naive no-change forecast (see Hamilton, 2009; Alquist and Kilian, 2010; Alquist et al., 2013). Overall, conclusions from prior studies suggest that changes in oil prices are inherently unpredictable and difficult to model, and as a result the current price of oil may be the best available forecast of future prices.

Given the challenges faced by past forecasting approaches it would be important to understand why oil prices are so hard to predict. The literature provides interesting insights (c.f. Hamilton, 2009). Crude oil prices are driven by a large set of dynamic and multidimensional factors including physical markets factors, financial markets factors and trading factors that are themselves often hard to predict, and may also have counteracting effects.

\footnotetext{
${ }^{5}$ http://blogs.marketwatch.com/thetell/2014/04/08/eia-raises-2014-forecast-on-wti-crude-oil-prices-tonearly-96/

${ }^{6}$ http://www.eia.gov/naturalgas/article/Nature_news_feature.pdf
} 
Perfect foresight is also hindered due to unexpected demand shifts in the global economy, supply disruptions, changes in oil production and inventory demand, geopolitical events, among other factors. These types of events create uncertainty about future supply or demand, which can lead to higher volatility in prices. Of course, accidental events such as refinery outages or pipeline problems adds to the unpredictability. Therefore, in accounting for the history of past oil supply and demand shocks emanating from various events, market participants are always assessing the possibility of future events and their potential impact on prices. In addition to the size and duration of a potential disruption, agents also consider the current stock levels and the ability of producers to offset a potential supply/demand shock. Furthermore, the forward-looking behavior of speculators and the quantification of speculative oil demand shocks can, at times, invalidate standard econometric models if speculators respond to information not available to the econometrician attempting to disentangle demand and supply shocks based on historical data (Kilian and Lee, 2014). Confounding this challenge, it is also difficult to relate changes in real oil prices to macroeconomic outcomes due to the presence of reverse causality from macro aggregates to oil prices (see Barsky and Kilian 2002; Kilian, 2009; Chatrath et al., 2016).

These challenges not withstanding, forecasting efforts have not entirely been in vain. Researchers report success by expanding the range of explanatory factors and integrating them into their models. Dees et al. (2007) model oil prices as a function of oil inventories and demand, OPEC production, producer quotas and production capacity. Ewing and Thompson (2007) focus on the relationship between macroeconomic variables and crude oil prices, and find oil prices to be procyclical - i.e., leading consumer prices but lagging industrial production activities. Kaufmann et al. (2008) study the potential effect of refinery utilization rate on crude oil prices and show that lower refinery rates correspond with higher crude oil prices. In adding to this mix, the role of speculation and forward looking behavior in crude oil prices have been carefully examined by various authors. Sari et al. (2011) use the VIX index as a proxy for global risk and find that oil prices are influenced by 
related commodities. Coleman (2012) finds positive relationships between crude oil prices and proxies for speculative and terrorist activities while controlling for fundamental and market parameters. More recently, Miao, et al. (2017) report how crude oil inventory announcements impact oil futures and options prices. There is also some evidence that forecasting models based on economic fundamentals work better at shorter horizons (up to 3 months); whereas, models based on the crack spread work better at longer horizons (between 12 and 24 months). Baumeister and Kilian (2015) present a combination approach with six different models that marginally improves the forecasting performance in comparison to the no-change forecast.

This paper contributes to the literature by using a relatively new methodology that optimally selects among various factors that underlie crude oil price movements. In aiding our investigation, we consider a wide range of potential explanatory factors that are popularly associated with oil prices. Our analysis employs weekly data, and for expository purposes classifies variables along six broad factor dimensions: supply, demand, financial market, commodities market, speculative, and political factors. Specifically, we employ the Least Absolute Shrinkage and Selection Operator (LASSO) method to generate out-of-sample forecasts. Our results indicate that the LASSO method yields superior forecasts, as observed by reductions in the mean squared prediction error relative to various benchmark models such as the the no-change forecast, EIA projections and futures market predictions. The results also provide insights into the temporal relationship between various influential factors and crude oil prices.

The remainder of the study is organized as follows: Section 2 provides an overview of the data used in the study and establishes the economic importance of variables that determine oil prices. The various forecasting models and approaches are described in Section 3, followed by discussion of empirical results in Section 4 . Section 5 concludes the paper. 


\section{Components of the Crude Oil Price Forecasting Mod- els}

We use the West Texas Intermediate (WTI) crude oil spot prices as the dependent variable, and 26 potential determinants or predictors that are classified into six broad groups. The description, sample frequency and data source for each variable are shown in Table 1. 7 Our data spans the period from January 04, 2002 to September 25, 2015. The model is estimated over various fixed length rolling windows (5, 6 and 7 years), which minimizes the odds of generating spurious regression estimates. Table 1 provides a list of various factors, corresponding descriptions and data source.

[Insert Table 1 Here]

Supply Factors: It is commonly believed that oil is an exhaustible resource. We consider the following supply factors: 1) Global crude oil production. The global crude oil production include both OPEC and non-OPEC production. The production of crude oil is often subject to geopolitical developments, as well as factors such as weather-related events, exploration and production (E\&P) costs, investments and innovations. According to 2014 estimates, OPEC member countries control $81 \%$ of the world's crude oil reserves, with the bulk of OPEC oil reserves being in the Middle East, amounting to around $66 \%$ of the OPEC total $]^{8}$ The non-OPEC members also play an increasingly important role. According to EIA, non-OPEC members represents about $60 \%$ of world oil production in $20159^{9}$ 2) Global crude oil export. Global crude oil export can be viewed as an additional measure of global

\footnotetext{
${ }^{7}$ Consistent with the prior literature (c.f. Kilian, 2010, Baumeister and Kilian, 2012, 2015; Chatrath et al., 2016), for daily and weekly data, we only keep the observations for each Friday. When dealing with lower frequency data, we carefully distinguish the data into "points in time" values and "totals over an interval" value. For example, "Global Stock" represents the stock of crude oil for each month and is categorized as "points in time "value. For these variables, we equal each Friday's value in specific month to its corresponding observed monthly value. When data represents totals over an interval, such as quarterly GDPs, the total values of the larger intervals are evenly distributed to the smaller intervals (for instance, monthly GDPs).

${ }^{8}$ See: http://www.opec.org/opec_web/en/data_graphs/330.htm

${ }^{9}$ See: EIA report: What drives crude oil prices? https://www.eia.gov/finance/markets/supplynonopec.cfm
} 
crude oil production. Whereas, the former set of variables provide a direct picture of supply, this measures the potential capacity for (excess) supply. Hallock et al. (2004) shows a strong relationship between the conventional oil production and the available export for the world. 3) OPEC surplus crude oil production capacity. According to EIA, the surplus crude oil production capacity by OPEC nations is a useful indicator of general market supply conditions. Excess production capacity tends to stabilize global markets, and helps mitigate supply disruptions that can occur from time to time. 4) Crude oil inventory. Several studies examine the role of crude oil inventory on prices (see, for example Hamilton, 2009; Kilian and Murphy, 2014). The accumulation of crude oil stock permit greater flexibility in responding to short-term supply shortages ${ }^{10}$ We include both the global crude oil closing stock and the U.S. crude oil inventory in our forecast. 5) U.S. refinery utilization rate. Kaufmann et al. (2008) find that the refining rate plays an important role in determining crude oil prices, because lower refinery utilization rate will lead to a preference for higher quality crude oil, putting upward pressure on prices. Note U.S. refining capacity represents about one-fifths of world capacity. 6) Baltic exchange dirty tanker index. We follow Breitenfellner et al. (2009) and Fan and $\mathrm{Xu}$ (2011) by using the Baltic exchange dirty tanker index to track the shipping rates for transportation of unrefined oil on representative routes. Lower index values generally correspond with declining oil prices.

Demand Factors: Demand factors have been shown to have a significant and positive influence on crude oil prices (see Hamilton, 2009; Hicks and Kilian, 2009; Kilian, 2009). We consider several demand factors: 1) GDP. Global economic growth are closely related with oil demand. We consider the GDPs of the U.S., China and the Euro area (19 countries), which together account for more than $60 \%$ of the global GDP. 2) Kilian index. Kilian (2009) develops an index that measures shifts in the demand for industrial commodities that are driven by the global business cycle. Specifically, the index is based on dry cargo single voyage ocean freight rates. 3) Steel production. World steel production has also been shown to be

\footnotetext{
${ }^{10}$ See: EIA report: "High inventories help push crude oil prices to lowest levels in 13 years" http://www.opec.org/opec_web/en/data_graphs/330.htm
} 
a reliable indicator of global economic activity (Ravazzolo and Vespignani, 2015). We use the world steel production, as well as regional steel production in the U.S., China and the Euro area, as an important proxy for economic activity. 4) ISM manufacturing index. The ISM Manufacturing Index is widely viewed as an indicator of the business cycle (Scotti, 2013). The index is based on surveys of more than 300 manufacturing firms conducted by the Institute of Supply Management. 5) Global crude oil imports. Global crude oil imports is another key factor that reflects the state of the economy. Ghosh (2009) find a long-run relationship between quantity of crude oil imports and the price of the imported crude, and document unidirectional causality between economic growth and crude oil imports.

Financial Market Factors: The relationship between financial market factors and oil prices can be complex. We consider the following three factors: 1) U.S. interest rates. Frankel (2006) find that crude oil prices are negatively related with interest rates. In particular, U.S. monetary policy can impact oil prices through its effect on both currency values and interest rates. We consider the three-month Treasury bill rate and the Federal fund rate in our study. 2) Exchange rates. The importance of the U.S. dollar exchange rate in influencing oil prices has been documented by Sadorsky (2000), and Wang and Wu (2012), among others. Studies indicate that a weaker dollar usually leads to higher oil prices as oil producers aim to regain the purchasing power of the export revenues that are denominated in U.S. dollars. In addition, the country whose currency appreciates against the U.S. dollar is likely to experience higher demand for crude oil due to reduced costs. We use the U.S. dollar index, computed as the weighted geometric mean of the dollar's value relative to select currencies that include the Euro, Japanese yen, British pound, Canadian dollar, Swedish Krona and Swiss Franc. 3) Stock market. Jones and Kaul (1996) and Sadorsky (1999) find that the stock market and oil prices tend to move together in the same direction, seemingly in response to global aggregate demand factors. Shifts in aggregate demand influence both corporate profits and the demand for oil. Following Hammoudeh and Li (2005) we use the S\&P 500 and MSCI World indexes, respectively as proxies for the U.S. and world equity 
markets.

Commodity Market Factors: It's been noted that there is a relationship between crude prices and the prices of other industrial commodities. Following Coleman (2012) and Baumeister and Kilian (2015), we select two indices in our forecasting models: 1) S\&P GSCI Non-Energy Index serve as a benchmark for investments in commodity markets. It consists of all commodities included in the S\&P GSCI index, with the exception of crude oil and natural gas. 2) CRB Raw Industrial Materials index (CRB Rind index) measures price movements in 22 basic commodities whose markets are believed to be sensitive to changes in economic conditions. The selection of the two indices, which exclude crude oil and natural gas, mitigates potential endogeneity problems in the forecasting models.

Speculative Factors: The existence of an active derivatives market that allows for risk sharing, price discovery and cost control is an important feature of crude oil markets. Over the past decade, and in particular after 2004, there has been an ineluctable trend toward greater financialization of commodity markets with inflows of large amounts of investments into commodity futures. Derivatives markets which spawn speculative activities are believed to exert an important influence on oil prices. Behind such appeals is the implicit belief that crude oil prices are impacted in a significant manner by factors other than the prevailing market demand and supply conditions (see Kaufmann, 2011; Kilian and Murphy, 2014). Following Coleman (2012), therefore, we use the ratio of trading volume of oil futures contracts to global oil production as a measure of speculative activities.

GeoPolitical Factor: Crude oil is commonly recognized as a commodity that is sensitive to geopolitical events. Although many different variables exist that may capture the geopolitical environment, we follow Coleman (2012) by using the total amount of terrorist attack in the Middle East and North Africa, which largely overlaps with OPEC countries ${ }^{11}$ as a proxy for geopolitical (in)stability. This data is obtained from the Global Terrorism Database at the University of Maryland, with details of individual international terrorist

\footnotetext{
${ }^{11}$ According to British Petroleum (2010), Middle East produces about one-third of the oil among the world, and its reserves account for about $60 \%$ of the total world reserves.
} 
incidents since 1970 .

\section{$3 \quad$ Forecasting Models}

\subsection{Benchmark 1: No-change Forecast}

Following the literature (see Alquist and Kilian 2010; Kilian and Lee 2014; Baumeister and Kilian, 2015), we focus on the real price of oil rather than log prices. This helps avoid log approximation errors when fitting the real price of oil. A commonly used benchmark for judging the performance of forecasting models is provided by the random walk model without drift. This model implies that changes in the spot price are unpredictable; so the best available forecast of future spot prices of crude oil is simply the current spot price:

$$
\hat{P}_{t+h \mid t}=P_{t}
$$

We consider three alternative forecasting benchmarks as described below.

\subsection{Benchmark 2: EIA Forecast}

The U.S. Energy Information Administration (EIA) of the Department of Energy (DOE) provides comprehensive oil price forecasts regularly that are closely followed by market participants. EIA constructs monthly and quarterly price forecasts, the Short-Term Energy Outlook (STEO), with horizons ranging from one month to two years ${ }^{12}$, The STEO are released on the first Tuesday following the first Thursday of each month. EIA analysts construct forecasts based on information such as current and near-term futures prices of crude oil, OPEC and non-OPEC production, global economic growth, crude oil stock, among other factors. It is worth noting that while EIA uses large-scale multi-equation econometric models

\footnotetext{
${ }^{12}$ STEO forecasts can be obtained from: https://www.eia.gov/outlooks/steo/outlook.cfm
} 
to estimate supply and demand conditions for crude oil in various energy markets, as well as employs a consensus mechanism to arrive at the final forecast.13

\subsection{Benchmark 3: Futures-based Forecast}

Market participants use oil futures prices to divine future spot prices. The futures-based forecast is generated as follows:

$$
\hat{P}_{t+h \mid t}=F_{t}
$$

where $F_{t}$ is the price of crude oil WTI futures contract that matures in $h$ periods and available at time $t$.

\subsection{Benchmark 4: Factor-based Model}

Factor-based models provide an alternative approach to forecast oil prices (see Baumeister and Kilian 2015). A full factor-based model includes all valid predictor variables relevant to the determination of crude prices. By definition, the full factor model is not parsimonious and is subject to significant collinearity problems due to the presence of strong correlations across variables. We consider this "kitchen sink" model as a benchmark for comparison purposes, and later refine this to include significant variables found from LASSO and stepwise regression methodologies.

$$
P_{t}=\alpha+\sum_{i=h}^{n} \beta_{t-i} P_{t-i}+\sum_{j=h}^{n} \gamma_{t-j} X_{t-j}+\varepsilon_{t}
$$

where the crude oil prices at time $t\left(P_{t}\right)$ is a function of its lagged terms and $s$ independent variables, namely $X_{t, j}, j=1, \ldots, s . \varepsilon_{t}$ refers to error term at time $t$, representing any potential temporary deviations from long term relationship that couldn't be explained by the model.

\footnotetext{
${ }^{13}$ Since EIA's forecasts only have monthly and quarterly horizons, in our study, we compare EIA's one (two) month(s) forecasts to our four (eight) weeks ahead forecasts made by each method.
} 
Note that this factor-based regression is in the form of a reduced-form one-dimensional vector autoregression (VAR) model with exogenous variables. The regular VAR model would be more appropriate when there are bidirectional interactions between the dependent and independent variables. In our study, given the relatively large number of factors that are employed, plus the unidirectional nature of influence for the majority of independent variables, we use the reduced-form VAR model.

\subsection{The LASSO Method}

The LASSO method is an innovative variable selection method in which the choice of predictive variables is carried out using an algorithmic procedure. It was first introduced by Tibshirani (1996) and has gradually found application in the energy area such as electricity consumption (Wang et al., 2007), electricity prices (Suard et al., 2010), and natural gas prices (Alfano et al., 2015).

The LASSO method adds a penalty term to the cost function which keeps the estimated value of the regression coefficients small, thus reducing the inflation in standard errors often found in the presence of multicollinearity. When selecting variables, LASSO minimizes the residual sum of squares subject to the sum of the absolute value of the coefficients being less than a constant. More specifically,

$$
\hat{\beta}^{L}=\operatorname{argmin}\left\{\sum_{i=1}^{n}\left(y_{i}-\alpha-\sum_{i=1}^{n} \beta_{j} x_{i j}\right)^{2}\right\}, \text { subject to } \sum_{j=1}^{p}\left|\hat{\beta}_{j}^{L}\right| \leqslant c(\text { Constant })
$$

This problem is equivalent to $\hat{\beta}^{L}=\operatorname{argmin}\left\{\sum_{i=1}^{n}\left(y_{i}-\alpha-\sum_{i=1}^{n} \beta_{j} x_{i j}\right)^{2}+\lambda \sum_{j}\left|\beta_{j}\right|\right\}, \lambda>0$, where $\lambda$ is chosen so that $\sum_{j=1}^{p}\left|\hat{\beta}_{j}^{L}\right|=c$, and each $\lambda$ corresponds to a unique LASSO parameter c.

When the LASSO parameter is small enough, some of the regression coefficients shrink to zero. Hence, the LASSO method selects only a subset of the regression coefficients for each LASSO parameter. The LASSO parameter $c>0$ controls the degree of shrinkage that is applied for the estimates. Tibshirani (1996) uses quadratic programming techniques to 
solve each lasso parameter of interest. Osborne et al. (2000) develops a "homotopy" method to estimate the parameters for all values of $c$. In this paper we employ a computationally efficient method developed by Efron et al. (2004), a variant of the "least angle regression" method to obtain a pre-determined sequence of LASSO solutions. All other LASSO solutions are obtained by linear interpolation from the sequence of LASSO solutions.

\subsection{Stepwise Regression Method}

For comparison purposes, we also estimate a stepwise regression using the same set of predictive factors. The stepwise regression method has been used for evaluating movements in crude prices (Alexandridis et al., 2008), electricity prices (Nan et al., 2014), heating energy consumption patterns (Filippin et al., 2013). In this study, we use the "bidirectional elimination" stepwise regression method to identify a subset of influential predictor variables. Essentially, this approach combines the backward elimination and forward selection methods, and simultaneously adds and deletes variables according to a pre-defined criterion at each step. Usually, this pre-defined criterion takes the form of a sequence of F-tests or ttests, but other techniques are also possible, such as adjusted R-square, Akaike information criterion (AIC), and Bayesian information criterion (BIC). In our analysis, the selection criterion is based on a specified significance level of the F-test. The default level is set at 0.15. If the removal of any variables results in an F-statistic that is not significant at the default level, then the variable whose removal yields the least significant F-statistic is removed and the algorithm proceeds to the next step. Otherwise, the variable that produces the most significant F-statistics will be added, provided that it is significant at the default entry level. 


\subsection{Forecast Evaluation Methods}

\subsubsection{Diebold-Mariano test}

Following previous studies we compare the reduction in Mean Squared Prediction Error (MSPE) of proposed models against the benchmark to assess forecast accuracy. If the MSPE of a particular model is significantly smaller compared to the benchmark forecast, it indicates that the proposed model yields more accurate forecasts than the benchmark model.

To examine whether the MSPE reductions are statistically significant between models, we use the Diebold-Mariano test (DM test) introduced by Diebold and Mariano (1995). The DM test begins with calculating the loss differentials between two forecasting methods by weighting the loss differentials equally. The loss differential for observation is defined by $d_{t}=g\left(e_{i, t \mid t-h}\right)-g\left(e_{j, t \mid t-h}\right)$, with $g(\cdot)$ as some arbitrary loss functions. $g\left(e_{i, t \mid t-h}\right)$ and $g\left(e_{j, t \mid t-h}\right)$ are the $h$ steps ahead forecast errors for method $i$ and $j$. The two forecasts have equal accuracy if and only if the loss differential has zero expectations for all $t$. We use the symmetric loss function to make this assessment. Following Khandakar and Hyn$\operatorname{dman}(2008)$, the $g(\cdot)$ with $h$ steps forward forecast is defined as $g\left(e_{i, t \mid t-h}\right)=e_{i t}^{2}$, and the loss differential series $d_{t}$ to be assumed normally distributed. The DM statistics can be derived as $D M=\frac{\bar{d}}{\sqrt{\widehat{\gamma_{0}} / h}} \sim N(0,1)$, where $\bar{d}=\frac{\sum_{i=1}^{n} d_{i}}{h}$ is the sample mean, and $\widehat{\gamma_{0}}$ is the consistent estimate of the variance of $h \bar{d}$. The null hypothesis versus the alternative hypothesis is: $H_{0}: E\left(d_{t}\right)=0, H_{1}: E\left(d_{t}\right) \neq 0$, for all t.

\subsubsection{Pesaran-Timmermann Test}

As an additional test, the directional accuracy of different forecasting models are compared to the success probability of 0.5 . If the directional accuracy of a model is greater than 0.5 , it performs better than a random coin toss, or the no-change forecast. We use the test provided by Pesaran and Timmermann (1992) to evaluate whether or not the improvement is statistically significant. 
Pesaran and Timmermann (1992) propose a non-parametric test to examine the ability of a forecasting model to accurately predict the direction of change. Denoting the series of interest as $y_{t}$ and its forecast as $x_{t}$, the general standardized test statistic for predictive performance is as follows:

$$
S_{n}=\frac{\widehat{P}-\widehat{P_{*}}}{\sqrt{\widehat{V}(\widehat{P})-\widehat{V}\left(\widehat{P_{*}}\right)}}
$$

where the parameters are calculated as:

$$
\begin{aligned}
\widehat{P} & =\frac{1}{n} \sum_{i=1}^{n} I\left(y_{t} x_{t}\right), \\
\widehat{P_{*}} & =\widehat{P_{y}} \widehat{P_{x}}+\left(1-\widehat{P_{y}}\right)\left(1-\widehat{P_{x}}\right), \\
\widehat{V}(\widehat{P}) & =\frac{1}{n} \widehat{P_{*}}\left(1-\widehat{P_{*}}\right), \\
\widehat{V}\left(\widehat{P_{*}}\right) & =\frac{1}{n}\left(2 \widehat{P_{y}}-1\right)^{2} \widehat{P_{x}}\left(1-\widehat{P_{x}}\right)+\frac{1}{n}\left(2 \widehat{P_{x}}-1\right)^{2} \widehat{P_{y}}\left(1-\widehat{P_{y}}\right) \\
& \quad+\frac{4}{n^{2}} \widehat{P_{y} \widehat{P}_{x}}\left(1-\widehat{P_{y}}\right)\left(1-\widehat{P_{x}}\right), \\
\widehat{P_{y}} & =\frac{1}{n} \sum_{i=1}^{n} I\left(y_{t}\right), \\
\widehat{P_{x}} & =\frac{1}{n} \sum_{i=1}^{n} I\left(x_{t}\right),
\end{aligned}
$$

The $S_{n}$ defined above follows the standard normal distribution and $I(\cdot)$ is the indicative function. Under the null hypothesis, $x_{t}$ is not able to predict $y_{t}$.

\section{Empirical Results}

\subsection{Forecasting Performance}

As a first step to estimating regression models, we analyze the stationarity properties of each variable using the Augmented Dickey Fuller (ADF) unit root test. The results are shown in 
Table 2. The ADF tests shows that for the majority of the variables under analysis they are stationary under lags, drift or trend options. For example, the Baltic Dirty Tanker Index is stationary with trend and lag 1. For variables that fail to reject the unit root hypothesis, we take the first difference in levels to ensure their stationarity before using them in our regression analysis.

[Insert Table 2 Here]

Table 3 shows the MSPE performance for each forecasting method with different forecasts horizons (1, 2, 4, 8 steps-ahead forecasts) using a 5-year moving window length for estimation. The results are compared with the no-change forecast (Panel A), the EIA forecast (Panel B), the futures-based forecast (Panel C), and the factor-based model forecast (Panel D). The MSPE ratios of the LASSO and Stepwise methods relative to each benchmark, as well as the DM test for the MSPE reduction significance, indicate that the LASSO method generate superior forecasting accuracy compared to the four alternative benchmarks, as well as the stepwise regression forecasting model. For example, using the 8-steps ahead forecast horizon, we observe that the LASSO method yields significant improvements compared to the no-change forecast and the futures forecast benchmarks, with MSPE ratios of 0.873 and 0.898, respectively. In addition, although not found to be statistically significant, LASSO generates better forecasting performance, with fewer variables, relative to the factor-based model. While the statistical significance of MSPE reductions cannot be fully evaluated for EIA forecasts because of the unmatched forecast dates between EIA reports (the first Tuesday following the first Thursday of each month) and our sample record (each Friday), the LASSO method still exhibits MSPE ratios that are less than one. For instance, the MSPE ratios for the 8-steps ahead forecasts is as low as 0.813, indicating superiority over the EIA forecast.

It is also interesting to note that the Stepwise regression method also provides MSPE ratios that are smaller than one; however, most of these ratios are greater than corresponding 
ratios from LASSO. Notably, the DM test show that the reduction in MSPE from the Stepwise method is not statistically significant, indicating that the forecast from this approach underperforms the LASSO model.

$$
\text { [Insert Table } 3 \text { Here] }
$$

Table 4 presents the Pesaran-Timmerman success ratio statistics for each method 4 These results show that all three models perform similarly, with success ratio between $53 \%$ to $60 \%$ that are statistically significant at the $10 \%$ level or better.

$$
\text { [Insert Table } 4 \text { Here] }
$$

\subsection{Factors Driving Crude Oil Prices}

The LASSO and Stepwise methodologies are useful in identifying a subset of important variables that are influential in determining crude oil prices. We decide to primarily focus our results on LASSO for several reasons. First, there is evidence that multi-collinearity problems are exacerbated for stepwise regression which could result in spurious regression results (c.f. Harrell, 2001). In contrast, LASSO adds an additional penalty term to the cost function which keeps the estimated value of the regression coefficients small, thereby reducing the inflation in standard errors often seen in the presence of correlated data. Second, in comparison to the stepwise method, DM tests indicate that LASSO yields significant MSPE reductions compared to the no-change forecast. This implies that LASSO method provides better and more consistent forecasting performance than the stepwise method. Third, the selection efficiency of variables under LASSO is found to be higher than the stepwise method (20.66\% versus $52.47 \%$ ). We believe the lower selection percentage of LASSO is useful in identifying a parsimonious representation of crude oil price determination. Fourth, despite underlying differences between the two methodologies, there is evidence of a fair degree of

\footnotetext{
${ }^{14}$ By definitions of the no-change forecasts and futures' forecasts, the success ratios for these two methods are non-existence or meaningless.
} 
overlap between the variables selected under LASSO and stepwise regression. The most frequently selected variables by LASSO all correspond with the top variables under stepwise regression, and variables that are less frequently selected variables by LASSO appear in the bottom quartile of variables identified by the stepwise regression model.

Our regression results are found to be stable in the presence of different rolling windows. For the purpose of discussion, we discuss results obtained from a 5-year moving window that includes a total of 456 forecasting periods. Table 5 shows parameters selected by LASSO, including selection frequency and selection percentage. The most frequently identified parameter is lagged-WTI prices, which is selected $100 \%$ of the time. This is in accordance with prior expectations. Specifically, given the relative superiority of the no-change forecast compared to other forecasting methods it is not entirely surprising that the lagged-WTI prices is the top selected variable.

\section{[Insert Table 5 Here]}

The importance of several demand factors are also evident. Within this group, we find world steel production, ISM index and Kilian index to be among the most important variables. We do not find GDP to contain predictive value. One possible reason for this result is that GDP growth rates are reported quarterly, and interpolation may have reduced its contributions to the forecasting model. In examining variables in the supply factor group, we find OPEC Surplus, Global Production, Baltic Dirty, and Capacity Utilization Rate to be never selected in the model; while the remaining three variables are also selected with less than $10 \%$ frequency. Within the commodity markets group, the CRB Rind index is the third most selected variable, which suggests the importance of common factors across the broader commodity market space. In examining the financial group, the dollar index appears to dominate other financial variables. The Federal Funds and T-bills interest rates are never selected. The geopolitical factor, proxied by the number of terrorist attacks in the Middle East and North Africa, is selected with relatively high frequency. Finally, the speculative factor does not seem to play an influential role in driving oil prices. 


\subsection{Time-Varying Influence of Driving Factors}

This section investigates whether or not the significant factors that explain crude oil price movements are found to vary over time. Since each group contain different number of explanatory variables, instead of using selection frequency, we examine their temporal influence by showing their quarterly selection percentage. During any specific time period, if one group shows higher selection percentage, it is likely that this group of variables are the driving force behind crude oil price movements. Given the relative lack of importance of speculative variables, they are not included in this analysis.

An examination of supply factors in Figure 1 indicate that their influence varies considerably over time. This finding is consistent with Kilian (2009) who suggests that oil price changes have been driven mainly by shocks in aggregate demand and precautionary demand, rather than by oil supply shocks. However, during specific time periods, like the price run up in 2007, they may be driven by stagnant supply as shown in Figure1 (also see Hamilton, 2009). Notably, our results are unable to implicate supply factors as the reason behind the steep price declines in 2008 and 2014.

[Insert Figure 1 Here]

Figure 2 shows the relationship between the demand factors and crude oil prices. Demand factors exert their influence across most time periods, but is especially evident after 2008 . Starting 2015, their influence is found to dissipate. Overall, demand factors seem to outweigh supply factor in determining crude oil prices.

[Insert Figure 2 Here]

Results from the financial factor group indicate the oversized importance of the dollar index relative to other variables. Its influence is particularly evident starting with the second quarter of 2011, as shown in Figure 3. We observe a 100\% selection of this variable for 7 
quarters. We can also conclude from the results that the recent oil prices decline since mid2014 has a lot to do with the relative strength of the US dollar. This finding is corroborated by the EIA ${ }^{15}$

[Insert Figure 3 Here]

Figure 4 documents a close relationship between commodity market factors and crude prices, especially from the onset of the second quarter of 2008. This is consistent with the findings of Barsky and Kilian (2002) and Baumeister and Kilian (2012). The results suggest the presence of common factors, such as fluctuations in the global business cycle, that influence prices of both crude oil and industrial commodities. Indirectly, the findings reinforce the importance of demand factors.

[Insert Figure 4 Here]

Finally, our results establish a significant link between geopolitical security risks and oil prices. Figure 5 show that this factor is selected only when crude oil prices are either rising or is at a relatively high level; but it doesn't seem to play a role in the recent decline of oil prices starting 2014.

[Insert Figure 5 Here]

\subsection{Forecasting Performance of 'Enlightened' Factor-based Model}

If individual factors selected by LASSO are truly informational, it follows that we should expect stronger results of a factor-based model that uses selected parameters identified by LASSO. To confirm this intuition, we examine whether the prediction accuracy of the factor model improves after dropping the less frequently selected variables. In this case, we only keep variables selected by LASSO at a $10 \%$ frequency or higher, and estimate a revised factor model to generate forecasts of crude oil prices. The forecasting performance of the factor model with selected factors, at different forecast horizons, is presented in Table 6 .

\footnotetext{
${ }^{15}$ https://www.eia.gov/finance/markets/financial_markets.cfm
} 
[Insert Table 6 Here]

The forecasting performance of the new (or 'enlightened') factor-based model is very encouraging. The MSPE of this model is much lower compared to benchmarks, and furthermore, we find the MSPE ratios to be lower than corresponding ratios in Table 3 . The success ratio also shows significant improvements compared to a fair toss, with a maximum success ratio of $59.3 \%$ in the one step-ahead forecast in Table 7 .

[Insert Table 7 Here]

\section{Results from Robustness Checks}

In order to establish the robustness of our results we re-estimate each model using alternative rolling window lengths of 6 and 7 years. The MSPE results, comparing the LASSO method with all benchmarks, for alternative window lengths are shown in Table 8 and 9 , respectively. Consistent with earlier results, for most forecast horizons, LASSO yields lower MSPE ratios relative to other benchmark models as well as the stepwise method ${ }^{16}$.

$$
\text { [Insert Tables } 8 \text { and } 9 \text { Here] }
$$

We also calculate corresponding success ratios for LASSO and the revised factor-based model using alternative rolling window lengths of 6 and 7 years ${ }^{17}$ Overall the results from robustness tests continue to affirm the significance of LASSO in improving the forecast accuracy of the factor-based model.

\section{Conclusions}

There is widespread agreement that fluctuations in energy prices carry important implications across a wide range of economic activities. Yet academic research appears to be

\footnotetext{
${ }^{16}$ The only non-compliant result (i.e., MSPE $>1$ ) is the 8-step ahead forecast when compared to the EIA forecast using the 7-year rolling window length.

${ }^{17}$ These results are available from the authors upon request.
} 
somewhat hamstrung on its ability to generate reliable forecasts of oil prices. However, this hasn't dissuaded commodity market participants to seek and identify important factors that drive crude oil price movements, and using this information to construct better price forecasting models. Our study finds that the LASSO method provides superior forecasting results compared to the no-change forecast and other econometric-based forecasting models. Relative to alternative models, LASSO yields statistically significant MSPE reductions as well as improvements in predicting directional movements in prices.

The identification of important factors by LASSO provide motivation to examine their time-varying influence on prices. We find that the lagged-WTI price is the most important determinant of crude oil prices. Our results also document that demand factors (specifically, world steel production, Kilian index and ISM index), commodity market factors (CRB rind index), financial factor (dollar index) and the geopolitical risk factor (incidence of terrorist attacks in the Middle East and North Africa) are among the most influential parameters. Collectively, these factors outweigh the importance of supply and speculative factors. An important implication of our finding is that the recent decline in oil prices (since mid-2014) can be attributed to a combination of demand, commodity market and financial-related variables. Finally, an 'enlightened' factor model that includes parameters selected by LASSO yields significant improvements in forecast accuracy, with success ratios of about $60 \%$.

We suggest several possible extensions to our study. First, one could try and implement a logistic-LASSO method to obtain further improvements on the success ratio (see Harrell 2001). Second, the conversion of data from relatively low frequency to high frequency may have resulted in loss of information that negatively impacted the forecast accuracy of this study. Therefore, we posit that an alternative selection of data at the same frequency might avoid the noise from interpolation. Third, it might be useful to try the simple moving average of prices as an additional way to utilize information contained in lagged prices (see Han, Hu and Yang, 2016). Fourth, it remains to be determined as to which subset of non-energy commodity prices is most informative in forecasting oil prices. Lastly, as suggested by Wang 
and Yang (2010), it might be interesting to examine whether trading profits can be generated using LASSO and other forecasting models. These issues are left unexplored in this study, but provide rich fodder for future research. 


\section{References}

[1] Alexandridis, A., Zapranis, A., Livanis, S., 2008. Analyzing crude oil prices and returns using wavelet analysis and wavelet networks. 7th Hellenic Finance and Accounting Association Conference. Conference Paper.

[2] Alfano, S.J., Rapp, M., Prollochs, N., Feuerriegel, S., Neumann, D., 2015. Driven by news tone? Understanding information processing when covariates are unknown: the case of natural gas price movements. Working Paper.

[3] Alquist, R., Kilian, L., 2010. What do we learn from the price of crude oil futures? Journal of Applied Econometrics 25, 539-573.

[4] Alquist, R., Kilian, L., Vigfusson, R.J., 2013. Forecasting the price of oil. Handbook of Economic Forecasting 2, 427-507.

[5] Barsky, R.B., Kilian, L., 2002. Do we really know that oil caused the great stagflation? A Monetary Alternative. NBER Macroeconomics Annual 2001, Volume 16, 137-198, MIT Press.

[6] Baumeister, C., Kilian, L., 2012. Real-Time forecasts of the real price of oil. Journal of Business and Economic Statistics 30, 326-336.

[7] Baumeister, C., Kilian, L., 2015. Forecasting the real price of oil in a changing world: A forecast combination approach. Journal of Business \& Economic Statistics 33, 338-351.

[8] Chatrath, A., Miao, H., Ramchander, S., Wang, T., 2016. An examination of the flow characteristics of crude oil: Evidence from risk-neutral moments. Energy Economics 54, 213-223.

[9] Coleman, L., 2012. Explaining crude oil prices using fundamental measures. Energy Policy 40, 318-324.

[10] Dees, S., Di, M., Pesaran, M.H., Smith, L.V., 2007. Exploring the international linkages of the euro area: a global VAR analysis. Journal of Applied Econometrics 22, 1-38.

[11] Diebold, F., Mariano, R., 1995. Comparing predictive accuracy. Journal of Business and Economic Statistics 13, 134-144.

[12] Efron, B., Hastie, T., Johnstone, I., Tibshirani, R., 2004. Least angle regression. The Annals of statistics 32, 407-499.

[13] Eika, T., Magnussen, K.A., 2000. Did Norway gain from the 1979-1985 oil price shock? Economic Modelling 17, 107-137.

[14] Ewing, B.T., Thompson, M.A., 2007. Dynamic cyclical comovements of oil prices with industrial production, consumer prices, unemployment, and stock prices. Energy Policy $35,5535-5540$. 
[15] Fan, Y., Xu, J.H., 2011. What has driven oil prices since 2000? A structural change perspective. Energy Economics 33, 1082-1094.

[16] Filippin, C., Ricard, F., Larsen, S.F., 2013. Evaluation of heating energy consumption patterns in the residential building sector using stepwise selection and multivariate analysis. Energy and Buildings 66, 571-581.

[17] Frankel, J.A., 2006. The effect of monetary policy on real commodity prices. National Bureau of Economic Research, No. w12713.

[18] Ghosh, S., 2009. Import demand of crude oil and economic growth: evidence from India. Energy Policy 37, 699-702.

[19] Hallock, J.L., Tharakan, P.J., Hall, C.A., Jefferson, M., Wu, W., 2004. Forecasting the limits to the availability and diversity of global conventional oil supply. Energy 29, 1673-1696.

[20] Hamilton, J.D., 2009. Understanding crude oil prices. Energy Journal 30, 179-206.

[21] Hammoudeh, S., Li, H., 2005. Oil sensitivity and systematic risk in oil-sensitive stock indices. Journal of Economics and Business 57, 1-21.

[22] Han, Y., Hu, T., Yang, J., 2016. Are there exploitable trends in commodity futures prices? Journal of Banking \& Finance 70, 214-234.

[23] Harrell, F.E., 2001. Regression modeling strategies: With applications to linear models, logistic regression, and survival analysis. Springer, New York.

[24] Hicks, B., Kilian, L., 2009. Did unexpectedly strong economic growth cause the oil price shock of 2003-2008? Journal of Forecasting 32, 385-394.

[25] Jones, C.M., Kaul, G., 1996. Oil and the stock markets. The Journal of Finance 51, $463-491$.

[26] Kaufmann, R. K., Dees, S., Gasteuil, A., Mann, M., 2008. Oil prices: The role of refinery utilization, futures markets and non-linearities. Energy Economics 30, 2609-2622.

[27] Kaufmann, R.K., 2011. The role of market fundamentals and speculation in recent price changes for crude oil. Energy Policy 39, 105-115.

[28] Khandakar, Y. and Hyndman, R.J., 2008. Automatic time series forecasting: the forecast Package for R. Journal of Statistical Software, 27(03), 1-22.

[29] Kilian, L., 2009. Not all oil price shocks are alike: disentangling demand and supply shocks in the crude oil market, American Economic Review 99, 1053-1069.

[30] Kilian, L., 2010. Explaining Fluctuations in Gasoline Prices: A Joint Model of the Global Crude Oil Market and the U.S. Retail Gasoline Market, Energy Journal 31, 87-104. 
[31] Kilian, L., Lee, T.K., 2014. Quantifying the speculative component in the real price of oil: The role of global oil inventories. Journal of International Money and Finance 42, 71-87.

[32] Kilian, L., Murphy, D.P., 2014. The role of inventories and speculative trading in the global market for crude oil. Journal of Applied Econometrics 29, 454-478.

[33] Miao, H., Ramchander, S., Wang, T. and Yang, J., 2017. The impact of crude oil inventory announcements on prices: Evidence from derivatives markets. Journal of Futures Markets, Forthcoming.

[34] Nan, F., Bordignon, S., Bunn, D.W., Lisi, F., 2014. The forecasting accuracy of electricity price formation models. International Journal of Energy and Statistics 2, 1-26.

[35] Osborne, M.R., Presnell, B., Turlach, B.A., 2000. On the lasso and its dual. Journal of Computational and Graphical Statistics 9, 319-337.

[36] Pesaran, M.H., Timmermann, A., 1992. A simple nonparametric test of predictive performance. Journal of Business \& Economic Statistics 10, 461-465.

[37] Pindyck, R.S., 1999. The long-run evolution of energy prices. The Energy Journal, 1-27.

[38] Radchenko, S., 2005. Oil price volatility and the asymmetric response of gasoline prices to oil price increases and decreases. Energy Economics 27, 708-730.

[39] Ravazzolo, F., Vespignani, J.L., 2015. A new monthly indicator of global real economic activity. Working Paper.

[40] Sadorsky, P., 1999. Oil price shocks and stock market activity. Energy Economics 21, 449-469.

[41] Sadorsky, P., 2000. The empirical relationship between energy futures prices and exchange rates. Energy Economics 22, 253-266.

[42] Sari, R., Soytas, U., Hacihasanoglu, E., 2011. Do global risk perceptions influence world oil prices? Energy Economics 33, 515-524.

[43] Scotti, C., 2013. Surprise and uncertainty indexes: Real-time aggregation of real-activity macro surprises. FRB International Finance Discussion Paper.

[44] Suard, F., Goutier, S., Mercier, D., 2010. Extracting relevant features to explain electricity price variations. 7th International Conference on the European Energy Market, $1-6$.

[45] Tibshirani, R., 1996. Regression shrinkage and selection via the Lasso. Journal of the Royal Statistical Society Series 58, 267-288.

[46] Wang, H., Li, G., Tsai, C.L., 2007. Regression coefficient and autoregressive order shrinkage and selection via the LASSO. Journal of the Royal Statistical Society Series B, 63-78. 
[47] Wang, T., Yang, J., 2010. Nonlinearity and intraday efficiency tests on energy futures markets. Energy Economics 32, 496-503.

[48] Wang, Y., Wu, C., 2012. Energy prices and exchange rates of the US dollar: Further evidence from linear and nonlinear causality analysis. Economic Modelling 29, 22892297. 


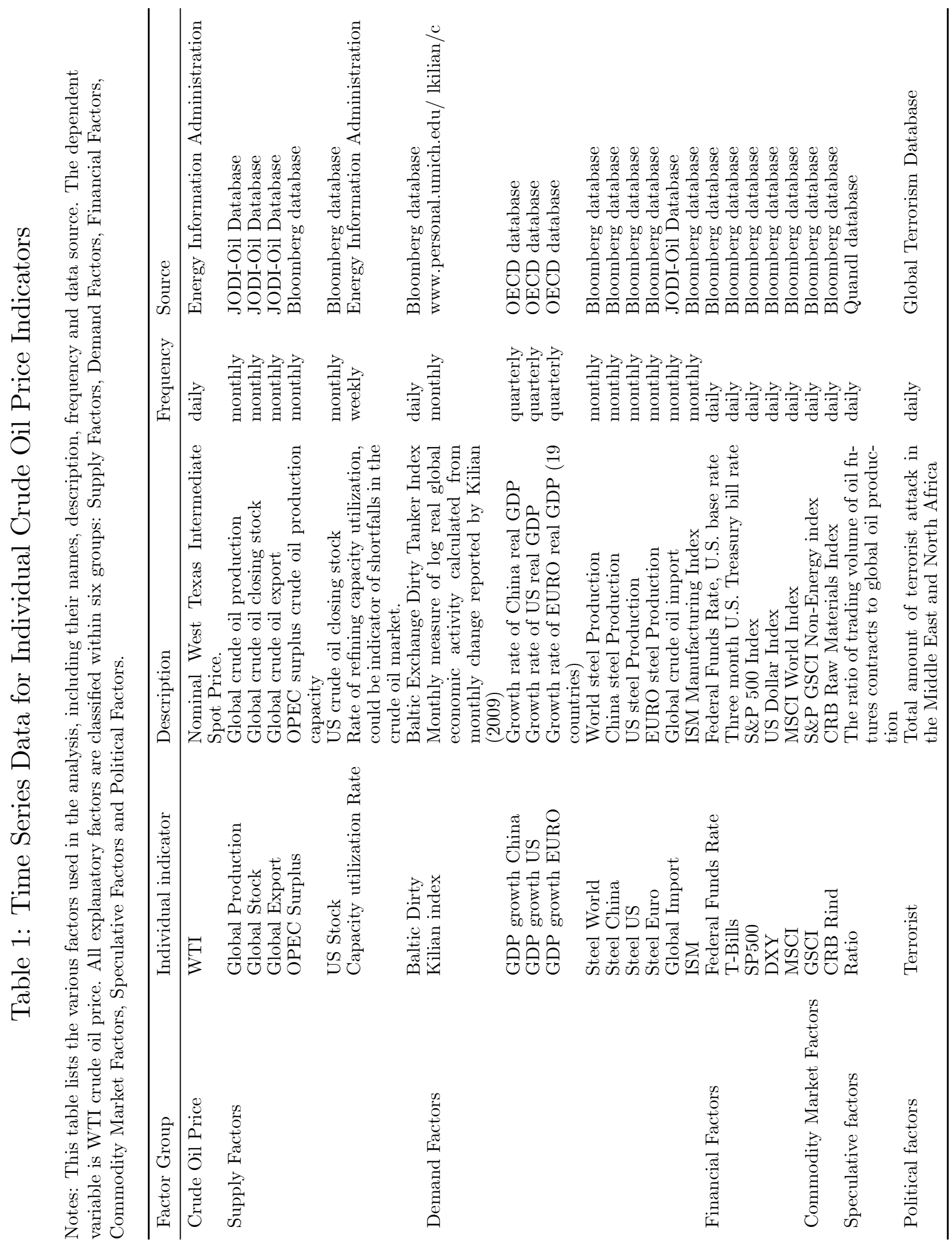




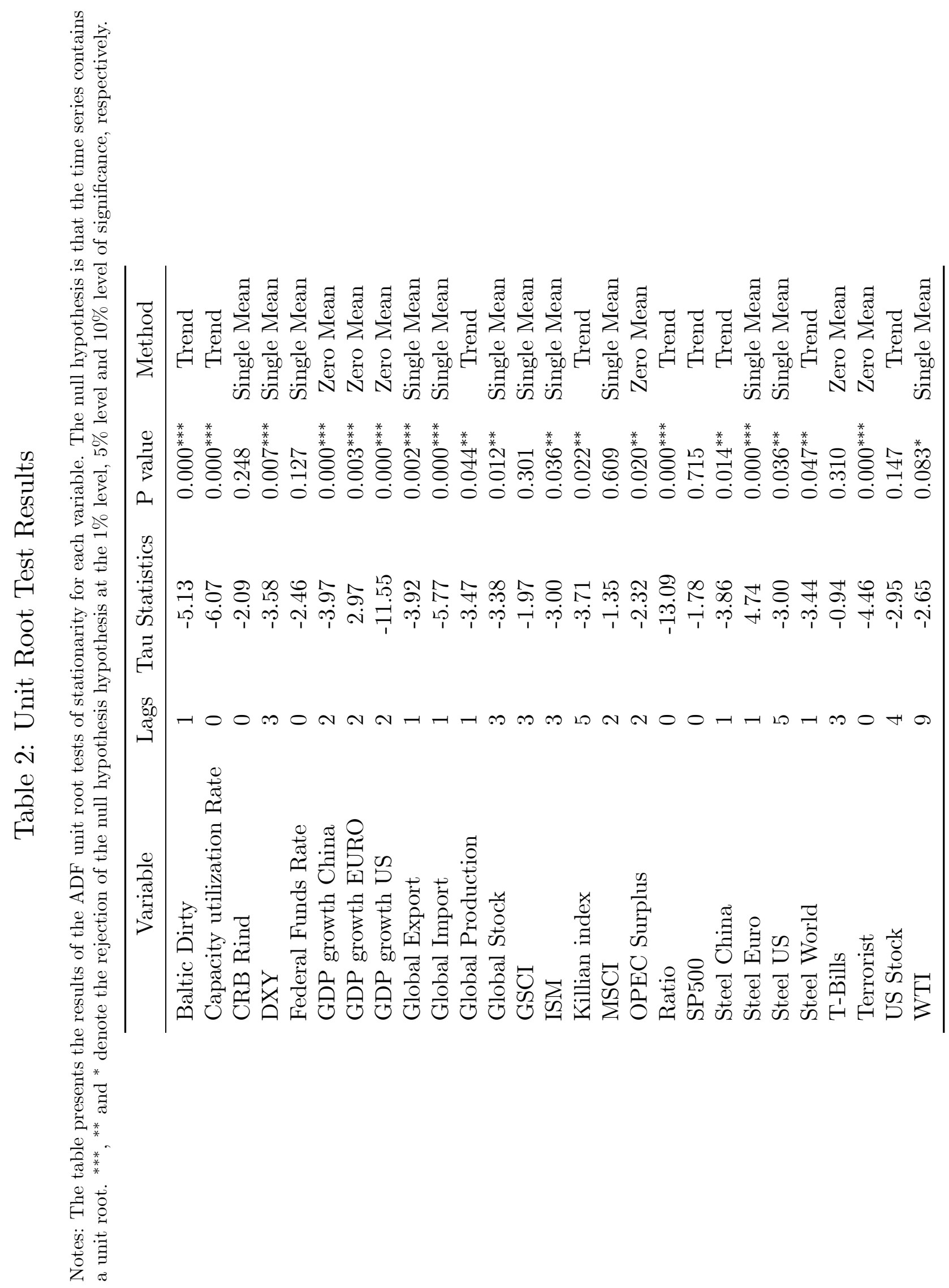




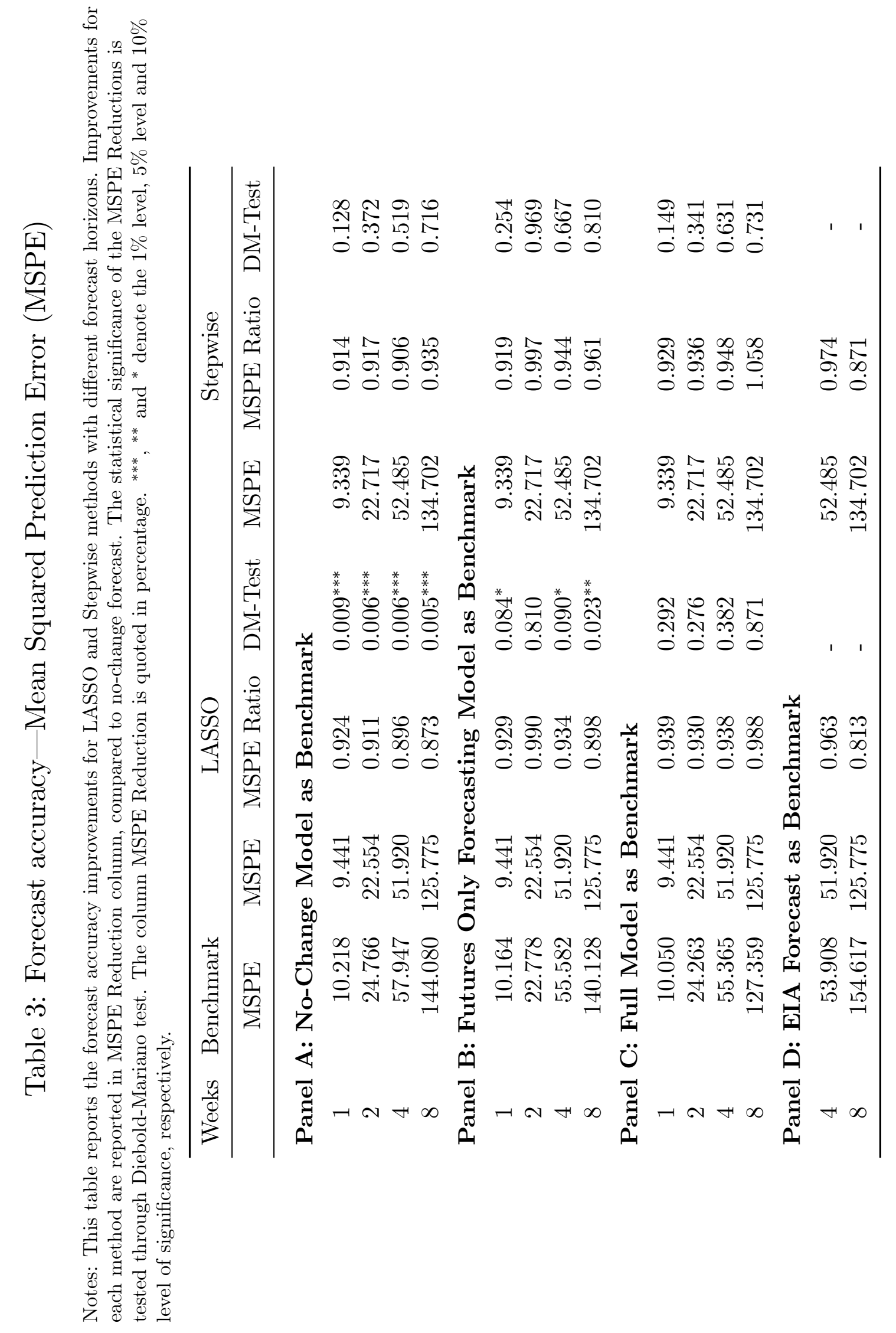




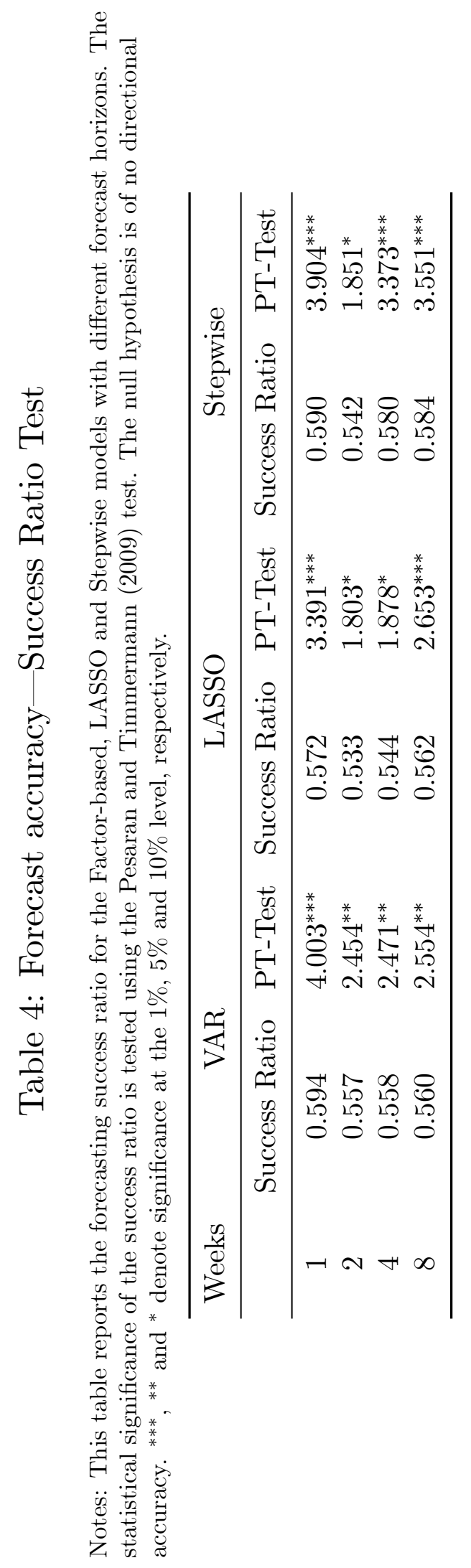




\section{Table 5: Variable selection from LASSO}

Notes: This table reports the most frequently selected factors with five year rolling window using the LASSO method. We only shows factors selected by LASSO at the $5 \%$ percent frequency or more. Factors are sorted by selected frequency.

\begin{tabular}{lcc}
\hline Variable name & Selected Frequency & Selected percentage \\
lag_WTI & 456 & 1.000 \\
Steel World & 345 & 0.757 \\
CRB Rind & 332 & 0.728 \\
ISM & 190 & 0.417 \\
Terrorist & 181 & 0.397 \\
DXY & 180 & 0.395 \\
Kilian index & 107 & 0.235 \\
Steel China & 67 & 0.147 \\
MSCI & 41 & 0.090 \\
Global Export & 34 & 0.075 \\
Global Stock & 23 & 0.050 \\
\hline
\end{tabular}




\section{Table 6: LASSO Selected Factor-based Model}

Notes: This table shows forecasting results using LASSO selected factors factor-based model. The forecasting results are compared with with no-change forecast, EIA forecast, Futures-based forecast, and the full factor-based models. Statistical signficance is provided by the Diebold-Mariano test. ${ }^{* * *},{ }^{* *}$ and ${ }^{*}$ denote significance at the $1 \%, 5 \%$ and $10 \%$ level, respectively.

\begin{tabular}{|c|c|c|c|c|}
\hline \multirow[t]{2}{*}{ Weeks } & \multirow{2}{*}{$\frac{\text { Benchmark }}{\text { MSPE }}$} & \multicolumn{3}{|c|}{ Selected Factors } \\
\hline & & MSPE & MSPE Ratios & DM-Tests \\
\hline \multicolumn{5}{|c|}{ Panel A: No-Change Model as Benchmark } \\
\hline 1 & 10.218 & 8.916 & 0.873 & $0.005^{* * *}$ \\
\hline 2 & 24.766 & 21.204 & 0.856 & $0.011^{* *}$ \\
\hline 4 & 57.947 & 47.758 & 0.824 & $0.010^{* *}$ \\
\hline 8 & 144.080 & 117.759 & 0.817 & $0.009^{* * *}$ \\
\hline \multicolumn{5}{|c|}{ Panel B: Futures Forecasting as Benchmark } \\
\hline 1 & 10.164 & 8.916 & 0.877 & 0.547 \\
\hline 2 & 22.778 & 21.204 & 0.931 & 0.234 \\
\hline 4 & 55.582 & 47.758 & 0.859 & $0.033^{* *}$ \\
\hline 8 & 140.128 & 117.759 & 0.840 & $0.024^{* * *}$ \\
\hline \multicolumn{5}{|c|}{ Panel C: Full Model as Benchmark } \\
\hline 1 & 10.050 & 8.916 & 0.887 & $0.019^{* *}$ \\
\hline 2 & 24.263 & 21.204 & 0.874 & $0.014^{* *}$ \\
\hline 4 & 55.365 & 47.758 & 0.863 & $0.012^{* *}$ \\
\hline 8 & 127.359 & 117.759 & 0.925 & 0.169 \\
\hline \multicolumn{5}{|c|}{ D: EIQA's Forecast as Benchmark } \\
\hline 4 & 53.908 & 47.758 & 0.886 & - \\
\hline 8 & 154.617 & 117.759 & 0.762 & - \\
\hline
\end{tabular}




\section{Table 7: Forecasting Accuracy of the LASSO Selected Factor-based Model - Success Ratio}

Notes: This table reports the forecasting success ratio for the LASSO selected factor-based model with different horizons. Statistical signficance of the success ratio is tested using the Pesaran and Timmermann (2009) test. The null hypothesis is of no directional accuracy. ${ }^{* * *},{ }^{* *}$ and ${ }^{*}$ denote significance at the $1 \%$, $5 \%$ and $10 \%$ level, respectively.

\begin{tabular}{ccl}
\hline Weeks & Success Ratio & PT-Test \\
\hline 1 & 0.593 & $3.989^{* * *}$ \\
2 & 0.551 & $2.190^{* *}$ \\
4 & 0.555 & $2.339^{* *}$ \\
8 & 0.583 & $3.501^{* * *}$ \\
\hline
\end{tabular}




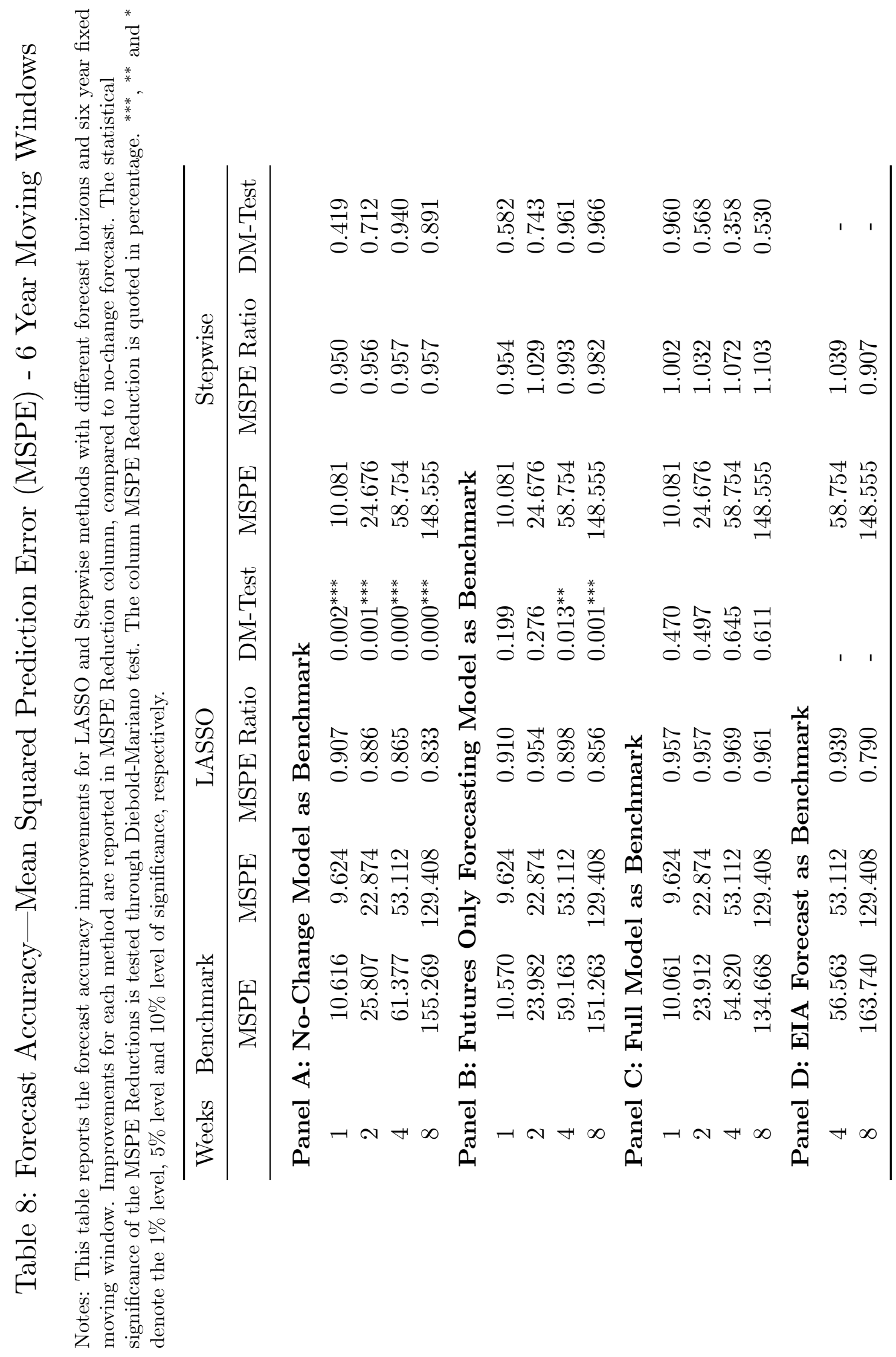




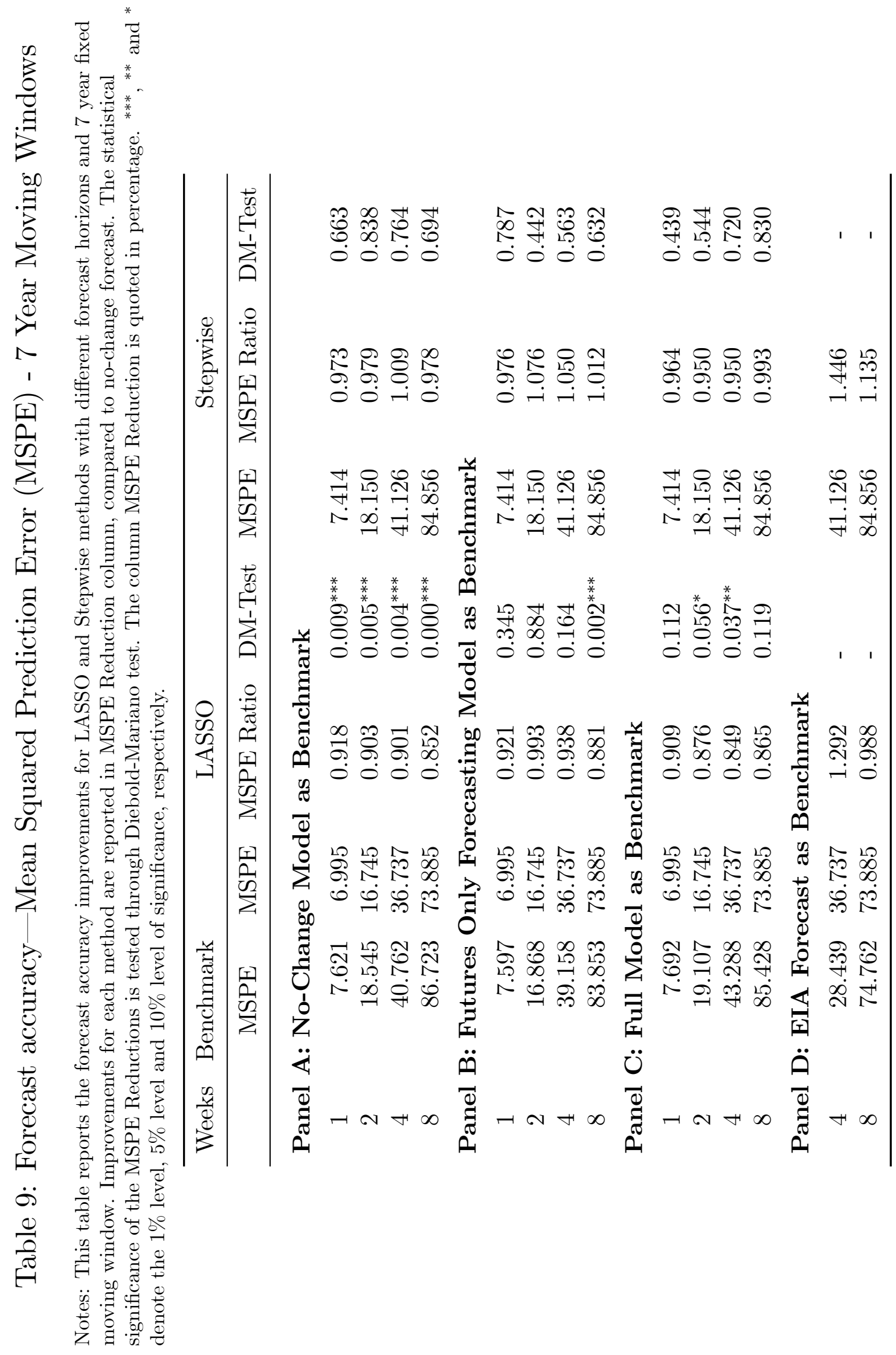




\section{Figure 1: Supply Factors and Crude Oil Prices}

Notes: The figure shows the relationship between quarterly crude oil prices and the percentage of inclusion of the Supply Factors in the LASSO model with five year moving windows. In the graph, the left Y-axis represents the percentage of selection of the Supply factors and the right Y-axis represents the crude oil price (quarterly average of weekly prices).

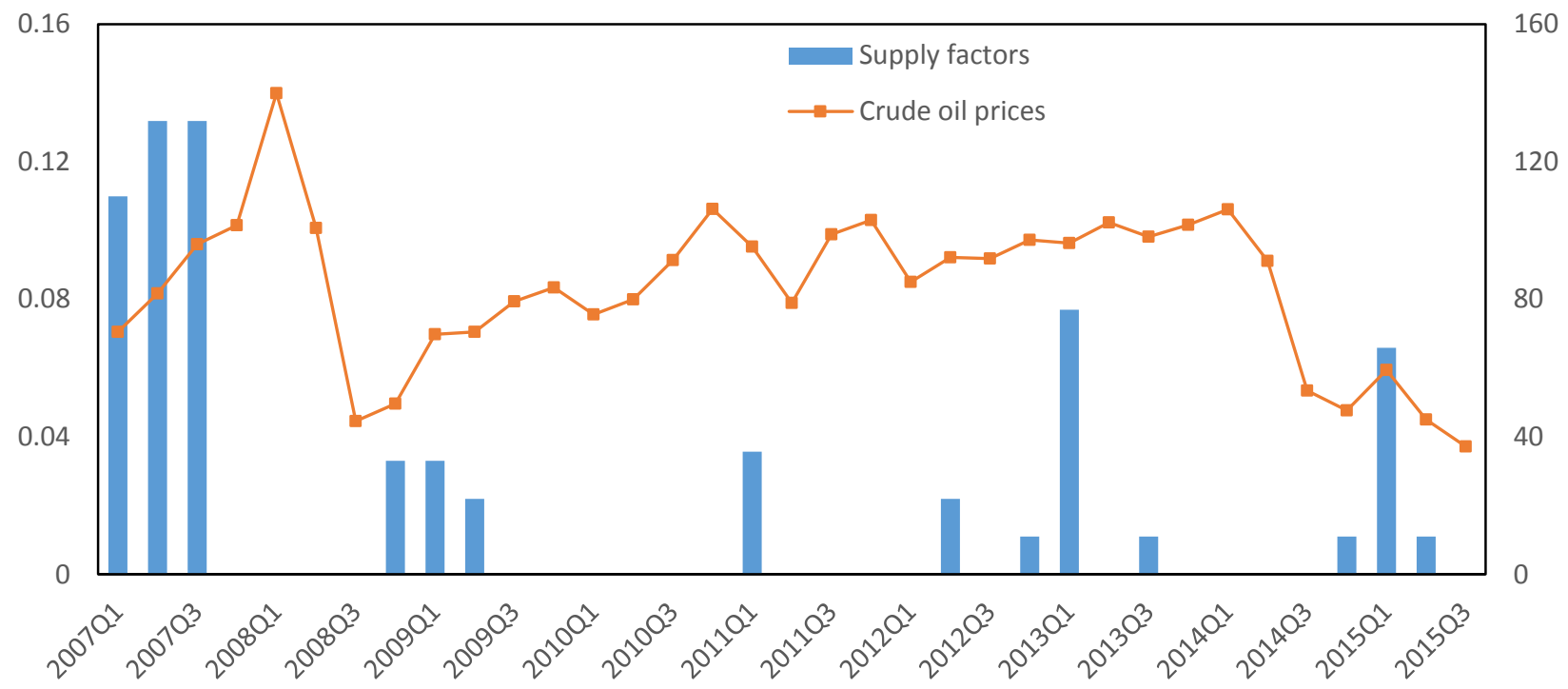




\section{Figure 2: Demand Factors and Crude Oil Prices}

Notes: The figure shows the relationship between quarterly crude oil prices and the percentage of inclusion of the Demand Factors in the LASSO model with five year moving windows. In the graph, the left Y-axis represents the percentage of selection of the Demand factors (quarterly average of weekly models) and the right Y-axis represents the crude oil price (quarterly average of weekly prices).

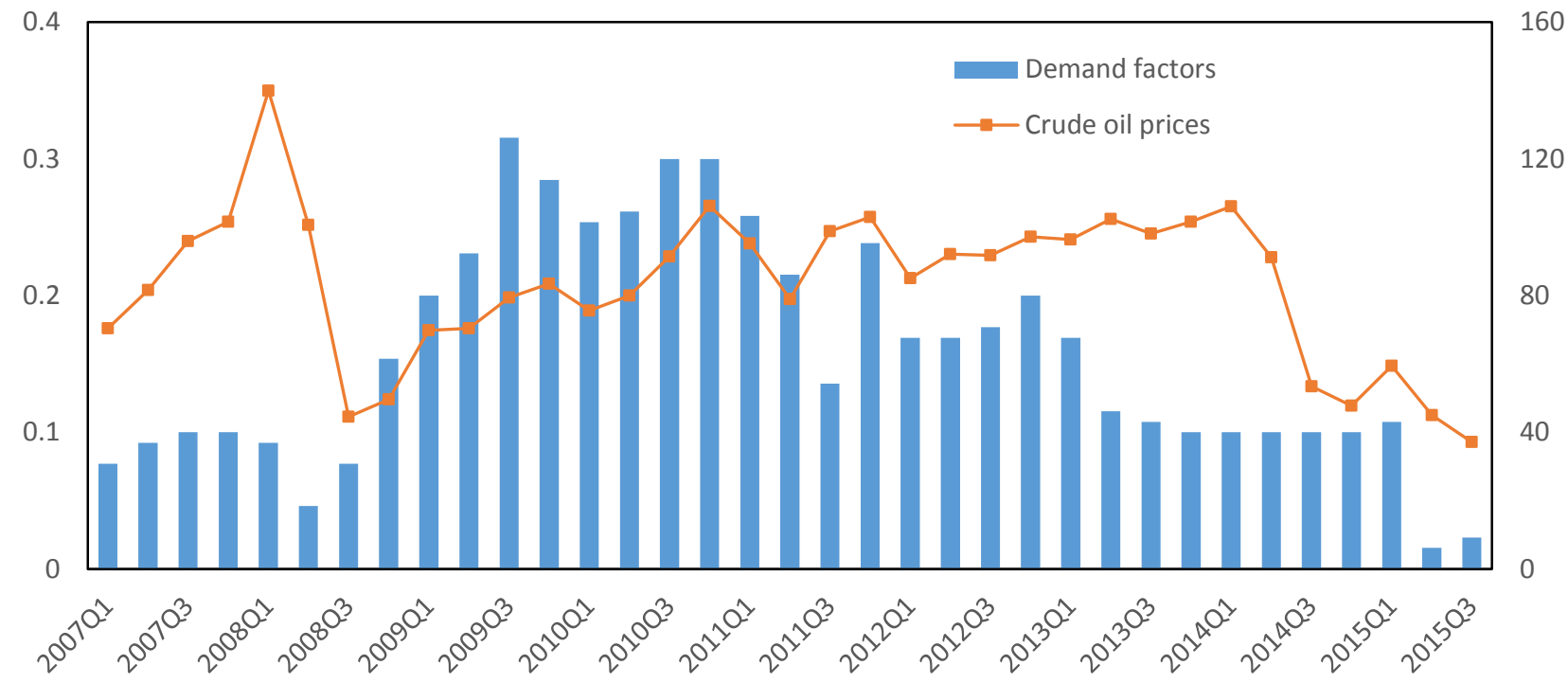




\section{Figure 3: Dollar Index and Crude Oil Prices}

Notes: The figure shows the relationship between quarterly crude oil prices and the percentage of inclusion of the Dollar Index (quarterly average of weekly models) in the LASSO model with five year moving windows. In the graph, the left Y-axis represents the percentage of selection of the Dollar Index and the right Y-axis represents the crude oil price (quarterly average of weekly prices).

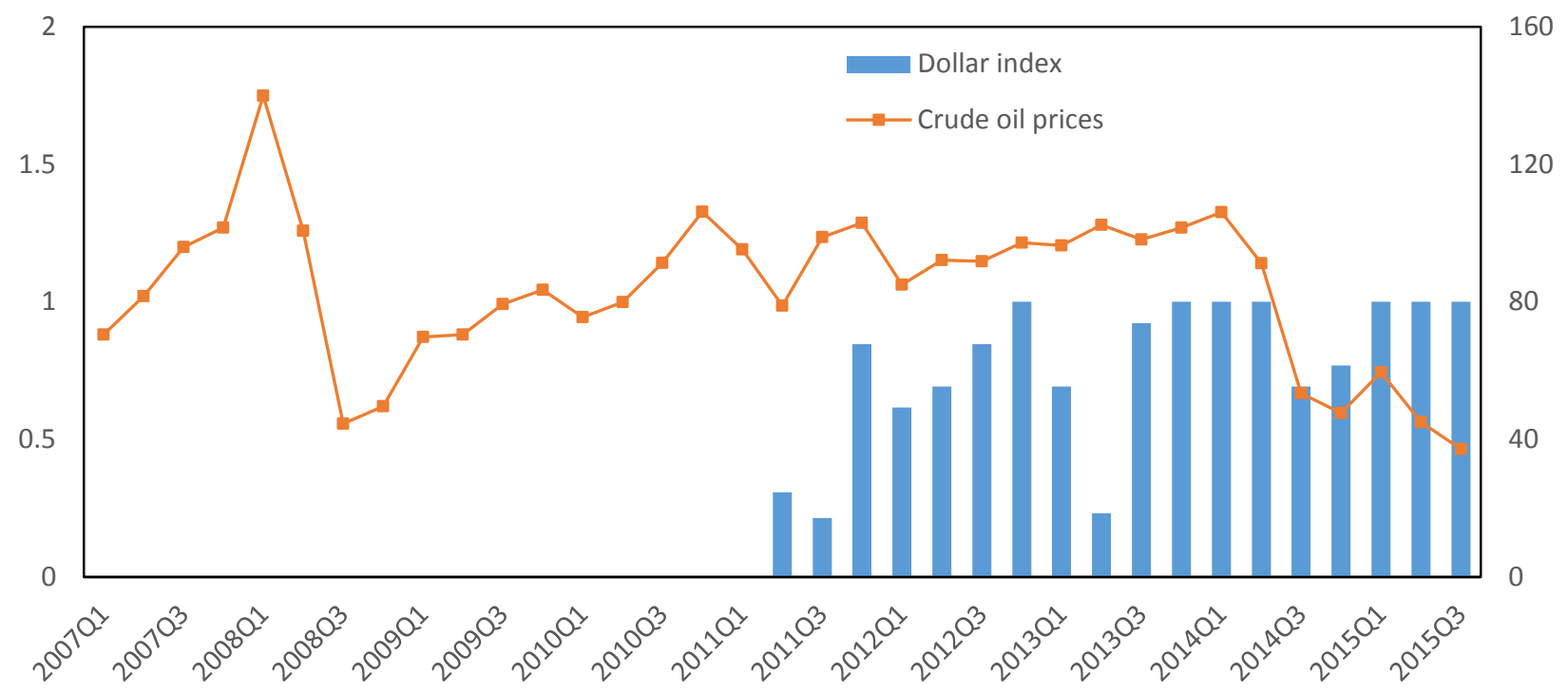




\section{Figure 4: Commodity Market Factors and Crude Oil Prices}

Notes: The figure shows the relationship between quarterly crude oil prices and the percentage of inclusion of the Commodity Market Factors (quarterly average of weekly models) in the LASSO model with five year moving windows. In the graph, the left Y-axis represents the percentage of selection of the Commodity Market Factors and the right Y-axis represents the crude oil price (quarterly average of weekly prices).

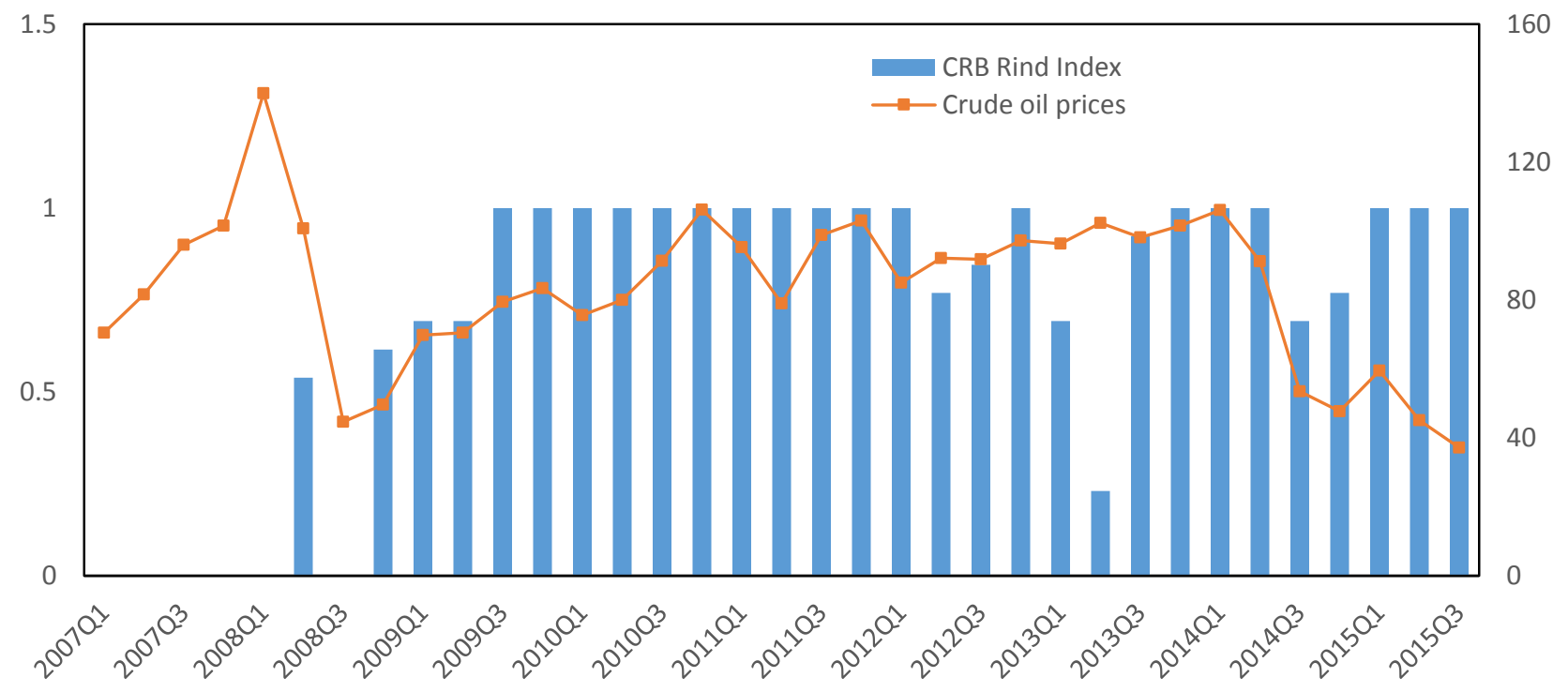




\section{Figure 5: Political Factors and Crude Oil Prices}

Notes: The figure shows the relationship between quarterly crude oil prices and the percentage of inclusion of the Political Factors (quarterly average of weekly models) in the LASSO model with five year moving windows. In the graph, the left Y-axis represents the percentage of selection of the Politics Factors and the right $\mathrm{Y}$-axis represents the crude oil price (quarterly average of weekly prices).

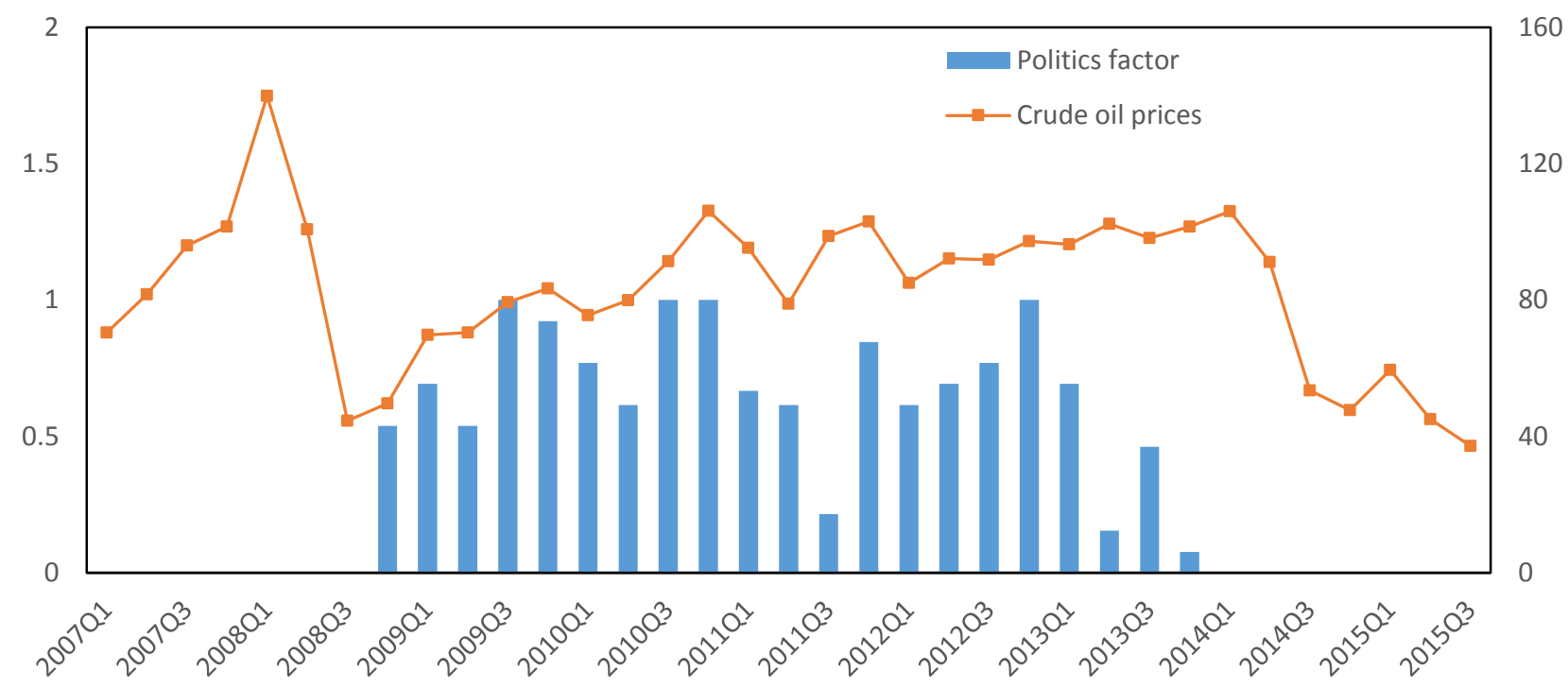

